\title{
Effect of low-concentration bleaching products on enamel bond strength at different elapsed times after bleaching treatment
}

\author{
María CURA, M Victoria FUENTES and Laura CEBALLOS \\ Department of Stomatology and Nursing, Faculty of Health Sciences, Rey Juan Carlos University, Avda. Atenas s/n, Alcorcón 28922, Madrid, Spain \\ Corresponding author, Laura CEBALLOS; E-mail: laura.ceballos@urjc.es
}

\begin{abstract}
This study evaluated the effects of several low-concentration bleaching products on microtensile bond strength ( $\mu$ TBS) to enamel at different elapsed times after the bleaching treatment. One hundred and fifty bovine incisors were divided into five groups: No treatment, 10\% carbamide peroxide (Opalescence), 10\% hydrogen peroxide (Opalescence Treswhite Supreme), 3\% carbamide peroxide plus lactoperoxidase (WhiteKin), or 3\% carbamide peroxide plus 2.7\% carbamide peroxide (Clysiden Kit Express). All treatments lasted 4 weeks. After bleaching treatment or non-treatment, teeth were restored immediately, at 1, 3, 7, or 14 days after bleaching and submitted to $\mu$ TBS test. Data were analyzed by ANOVA and Tukey's test $(p<0.05)$. For WhiteKin and Clysiden, $\mu$ TBS to enamel was significantly reduced immediately, at 1, 3 and 7 days after bleaching. At 14 days after bleaching, similar $\mu$ TBS values were obtained regardless of bleaching product. Therefore, while over-the-counter (OTC) products might affect bond strength to enamel, this effect was no longer observed after 14 days.
\end{abstract}

Keywords: Tooth bleaching agents, Enamel bond strength, Over-the-counter bleaching products

\section{INTRODUCTION}

Presently, dental bleaching is a cosmetic treatment that has aroused great interest in our patients. There are three main approaches to vital tooth bleaching: dentistsupervised nightguard bleaching, in-office or power bleaching, and use of over-the counter (OTC) bleaching products $^{1)}$.

Since the publications of Haywood and Heymann in 1989, nightguard vital bleaching has become the most commonly used method highly preferred by dentists ${ }^{2}$. According to published literature, the standard bleaching agent used is $10 \%$ carbamide peroxide as it demonstrates excellent and stable results with a very low incidence of side effects ${ }^{1,3-7)}$.

To address patients' desire for a more attractive smile with whiter teeth, the industry has since offered an increasing number of OTC bleaching products. Although they are a lower-cost alternative to dentist-supervised bleaching, OTC bleaching products enhance or maintain the whitening effect which is otherwise achieved with professional treatment ${ }^{8}$. These products come in the form of gels, rinses, gums, dentifrices, whitening strips, preloaded trays, or paint-on-films. They contain lowconcentration hydrogen peroxide or carbamide peroxide as the active bleaching agent ${ }^{2,8-12)}$. The growing number and great variability in composition and presentation of these self-applied whitening products increases the difficulty for dentists to be intimately acquainted with them. Many OTC products were not submitted to longterm independent clinical testing, and are consequently of questionable efficacy and/or safety ${ }^{2,8-11}$. Moreover, while having free access to OTC products, many people are not suitably warned by clinicians about the possible harmful effects of these products ${ }^{9}$.

Numerous studies have reported on reduced bond strength of resin composites to bleached enamel ${ }^{13-18)}$. Although hydrogen or carbamide peroxide is present in a low concentration in OTC products, their continuous use and interaction with enamel may alter the latter's adhesiveness ${ }^{19}$. Resin tags formed in bleached and etched enamel were described as less defined, more fragmented, and shallower than in unbleached enamel ${ }^{13)}$. Various reasons may account for this deleterious effect: erosive potential of OTC products because of their acidic $\mathrm{pH}^{20)}$, presence of residual oxygen in bleached enamel ${ }^{13)}$, or that peroxide-containing bleaching agents affect the organic phase of enamel ${ }^{17)}$. Therefore, whenever a treatment involving an adhesive procedure to enamel needs to be performed (such as composite restorations, porcelain veneers luting, or orthodontic brackets bonding), it is of paramount importance that dentists ask their patients if they use OTC bleaching products - since adhesives are applied with prior acid etching ${ }^{21,22)}$

On the other hand, the negative effect of peroxides on enamel adhesive capacity is reportedly reversible. Thus, waiting periods ranging from $24 \mathrm{~h}$ to 4 weeks have been recommended before performing adhesive procedures on bleached enamel ${ }^{13,16,23-25)}$.

The aim of the present study was to determine the effects of four low-concentration bleaching products, two dentist-supervised and two OTC, on $\mu$ TBS to enamel, and the influence of elapsed time between the end of bleaching treatment and the adhesive procedure on bond strength. Changes in chemical composition and microstructure of enamel surfaces treated with bleaching products and etched with phosphoric acid were also analyzed. We hypothesized that $\mu$ TBS to enamel would not be affected by the bleaching product used nor by the time elapsed between the end of bleaching treatment and the adhesive procedure. In addition, it was hypothesized that calcium (Ca) and phosphorus $(\mathrm{P})$ content and 
superficial morphology of acid-etched enamel would not be affected by the bleaching product used.

\section{MATERIALS AND METHODS}

One hundred and fifty bovine incisors without enamel cracks or hypoplasia were selected for this study. Bovine teeth have been used as human enamel substitutes in studies that evaluated the bond strengths of restorative materials after bleaching ${ }^{9,13,18,21,23,26)}$. Human and bovine teeth not only yielded comparable values in a microtensile bond strength test ${ }^{27)}$, they also have a similar chemical composition $^{28)}$.

Crowns were separated from the roots and stored in a thymol solution at $4^{\circ} \mathrm{C}$ for a duration no longer than 6 months since their extraction.

\section{Experimental groups}

Bovine incisors were randomly divided among the following experimental groups ( $n=30$ per group) according to the bleaching treatment performed. Compositions and application modes of the bleaching products tested are shown in Tables 1 and 2. All bleaching treatments were performed in accordance with manufacturers' instructions.

Group 1. No bleaching product was applied (control).

Group 2. Teeth were bleached with a 10\% carbamide peroxide gel (Opalescence 10\%, Ultradent Products, South Jordan, UT, USA). Gel was applied in individual trays $8 \mathrm{~h}$ per day.
Group 3. Teeth were bleached with a 10\% hydrogen peroxide gel (Opalescence Treswhite Supreme, Ultradent Products). Proprietary trays included in the product kit were adapted to each tooth, and gel was applied for 45 min per day.

Group 4. Teeth were brushed for $3 \mathrm{~min}$, three times per day, using a medium toothbrush (Colgate $360^{\circ}$, Colgate Palmolive, Madrid, Spain) and a toothpaste-and-gel mixture. Toothpaste and gel (WhiteKin, Kin, Barcelona, Spain) contained 3\% carbamide peroxide and lactoperoxidase. After toothbrushing, mouthwash was applied for $1 \mathrm{~min}$.

Group 5. Teeth were treated with a $3 \%$ carbamide peroxide toothpaste and a $2.7 \%$ carbamide peroxide solution and gel (Clysiden Kit Express, Ern, Barcelona, Spain). Teeth were brushed for $3 \mathrm{~min}$, three times per day, using a medium toothbrush (Colgate $360^{\circ}$ ) and with the toothpaste and solution mixed together. After toothbrushing, gel was applied for $30 \mathrm{~s}$.

For teeth in Groups 1 to 3, they were brushed for 2 min -twice per day - using a medium toothbrush (Colgate $360^{\circ}$ ) and with an approximate quantity of $1.5 \mathrm{~mL}$ of a 1,450-ppm fluoride paste (Dermocosmetic Korott, Alicante, Spain).

All bleaching treatments were performed for 4 weeks. During this time, teeth were stored in artificial

Table 1 Compositions of bleaching products tested in this study

\begin{tabular}{|c|c|}
\hline Product & Composition \\
\hline $\begin{array}{l}\text { Opalescence } \\
\text { (Ultradent) }\end{array}$ & Carbamide peroxide, sodium hydroxide \\
\hline $\begin{array}{l}\text { Opalescence Treswhite } \\
\text { Supreme (Ultradent) }\end{array}$ & Carbamide peroxide, sodium hydroxide, glycerin \\
\hline $\begin{array}{l}\text { WhiteKin } \\
\text { (Kin) }\end{array}$ & $\begin{array}{l}\text { Gel: glycerin, water, cellulose gum, PEG-60 (hydrogenated castor oil), carbamide peroxide (3\%), } \\
\text { flavor, anethole, disodium EDTA (etildiaminotetraacetic acid), tromethamine } \\
\text { Paste: water, sorbitol, hydrated silica, glycerin, lactoperoxidase, cocamidopropyl betaine, } \\
\text { titanium dioxide, flavor, xylitol, xanthan gum, sodium fluoride (1450 ppm), sodium } \\
\text { methylparaben, sodium ethylparaben, sodium saccharin, eugenol } \\
\text { Mouthwash: water, sorbitol, glycerin, PEG-40 (hydrogenated castor oil), PVP } \\
\text { (polyvinylpyrrolidone), xylitol, panthenol, methylparaben, flavor, sodium fluoride (1000 } \\
\text { ppm), citric acid, ammonium glycyrrhizate, cetylpyridinium chloride, disodium EDTA } \\
\text { (etildiaminotetraacetic acid), sodium propylparaben, sodium saccharin, sodium sulfite, } \\
\text { limonene, benzyl alcohol, eugenol }\end{array}$ \\
\hline $\begin{array}{l}\text { Clysiden Kit Express } \\
\text { (Ern) }\end{array}$ & $\begin{array}{l}\text { Paste: water, sorbitol, hidrated silica, glycerin, PEG-12 (dimethicone), sodium lauryl sulfate, } \\
\text { limonene flavor, cellulose gum, pvm/Ma copolymer, titanium dioxide, sodium fluoride } \\
\text { (1463 ppm), papain, sodium saccharin, triclosan, sodium methilparaben, } \\
\text { trisodium phosphate, sodium propylparaben } \\
\text { Solution: carbamide peroxide (3\%), excipients c.s.p. } \\
\text { Gel: alcohol, water, PEG-12 (dimethicone), glycerin, carbomer, phosphoric acid, } \\
\text { BHT (butylated hydroxytoluene), flavor, carbamide peroxide }(2.7 \%)\end{array}$ \\
\hline
\end{tabular}


Table 2 Application modes and characteristics of bleaching products used in this study

\begin{tabular}{|c|c|c|c|c|}
\hline Product & Presentation & Bleaching agent & Application & $\mathrm{pH}$ \\
\hline $\begin{array}{l}\text { Opalescence } \\
\text { (Ultradent) }\end{array}$ & Gel & CP $10 \%$ & $\begin{array}{l}\text { Wear customized tray with the } \\
\text { product for } 8 \mathrm{~h} \text { a day }\end{array}$ & $6-6.5$ \\
\hline $\begin{array}{l}\text { Opalescence Treswhite } \\
\text { Supreme (Ultradent) }\end{array}$ & Gel-tray & HP $10 \%$ & $\begin{array}{l}\text { Wear preloaded tray for } 45 \\
\text { min a day }\end{array}$ & $6-6.5$ \\
\hline $\begin{array}{l}\text { WhiteKin } \\
\text { (Kin) }\end{array}$ & $\begin{array}{l}\text { Toothbrush (gel+paste) } \\
\text { followed by a } \\
\text { Mouthwash }\end{array}$ & $\begin{array}{c}\mathrm{CP} 3 \%+ \\
\text { lactoperoxidase }\end{array}$ & $\begin{array}{l}\text { Toothbrush: Brush } 3 \text { times/day } \\
\text { for } 3 \text { min. } \\
\text { Mouthwash: Rinse for one min } \\
\text { with } 15 \mathrm{~mL} \text { of the product, once } \\
\text { a day, after brushing teeth with } \\
\text { Whitekin gel+toothpaste }\end{array}$ & $\begin{array}{c}\text { Paste: } 6 \\
\text { Gel: } 5-5.5 \\
\text { Mouthwash: } \\
\text { 5-5.5 }\end{array}$ \\
\hline $\begin{array}{l}\text { Clysiden Kit Express } \\
\text { (Ern) }\end{array}$ & $\begin{array}{c}\text { Toothbrush } \\
\text { (paste+solution) } \\
\text { followed by a } \\
\text { Paintbrush (gel) }\end{array}$ & $\begin{array}{l}\text { CP } 3 \% \text { and } \\
\text { CP } 2.7 \%\end{array}$ & $\begin{array}{c}\text { Toothbrush: Brush } 3 \text { times/day } \\
\text { for } 3 \text { min } \\
\text { Applied } 30 \text { s of Gel after each } \\
\text { toothbrush. }\end{array}$ & $\begin{array}{l}\text { Paste: } 5.5-6 \\
\text { Solution: } 4.5 \\
\text { Gel:2.5 }\end{array}$ \\
\hline
\end{tabular}

saliva (Salivart, Fineman, Madrid, Spain) at $37^{\circ} \mathrm{C}$. It was composed of carboxymethylcellulose, sorbitol, sodium chloride, potassium phosphate, calcium dihydrogen chloride, magnesium hexahydrogen chloride, and potassium dihydrogen phosphate ${ }^{16)}$.

Determination of the $\mathrm{pH}$ values of all bleaching products tested was done using $\mathrm{pH}$ indicator strips (Panpeha, Sigma-Aldrich, Seelze, Germany), and three $\mathrm{pH}$ measurements were performed for each product.

\section{Microtensile bond strength test}

To determine the influence of elapsed time from end of bleaching treatment to the adhesive procedure on $\mu \mathrm{TBS}$ to enamel, six teeth were randomly selected from each experimental group. They were assigned to different subgroups depending on when the adhesive procedure was carried out: immediately, at 1, 3, 7 or 14 days after the bleaching treatment ended. All teeth were brushed twice per day and kept in artificial saliva at $37^{\circ} \mathrm{C}$ until the adhesive procedure was performed.

\section{Adhesive procedure}

To obtain specimens which were sufficiently long for attachment to the $\mu$ TBS measurement device, pulp chambers were filled with a resin composite and lingual surfaces were also restored with the same material.

Labial surfaces were mechanically ground with \#600 silicon carbide papers (Beta, Buehler, Lake Bluff, IL, USA) under running water to obtain flat enamel surfaces of $6 \mathrm{~mm} \times 8 \mathrm{~mm}$. They were etched with $36 \%$ phosphoric acid (Conditioner 36, Dentsply DeTrey, Konstanz, Germany) for $30 \mathrm{~s}$ and washed with an airwater spray. Excess water was removed. An adhesive, Adper Scotchbond 1 XT (3M ESPE, St Paul, MN, USA; also named as Adper Single Bond Plus Adhesive in USA and Adper Single Bond in Latin America), was applied according to manufacturer's instructions and lightcured for $20 \mathrm{~s}$ with a LED unit using the HIGH mode of $1,200 \mathrm{~mW} / \mathrm{cm}^{2}$ (Bluephase, Ivoclar Vivadent, Schaan,
Liechtenstein).

After light-curing, a microhybrid resin composite (Filtek Z250, 3M ESPE) was placed on the treated surface in two increments of $2 \mathrm{~mm}$ each. Each increment was light-cured with the same LED unit using the HIGH mode of $1,200 \mathrm{~mW} / \mathrm{cm}^{2}$.

\section{2. $\mu$ TBS measurement}

After $24 \mathrm{~h}$ of water storage following the adhesive procedure, all specimens were sectioned in both $\mathrm{x}$ and $y$ directions perpendicularly to the adhesive interface, using a water-cooled diamond saw (IsoMet $5000)$, to obtain beams with a cross-sectional area of approximately $1 \mathrm{~mm}^{2}$ (5 to 8 beams per tooth). Exact dimensions of the beams were measured using a digital caliper (Mitutoyo Corp., Kanagawa, Japan). Each beam was attached to a device for microtensile testing with a cyanocrylate adhesive (Loctite Super Glue-3, Henkel, Düsseldorf, Germany) and subject to the microtensile test in a universal testing machine (Instron 3345, Instron Corp, Canton, MA, USA) at a crosshead speed of $1 \mathrm{~mm} / \mathrm{min}$. Bond strengths were calculated in MPa, and specimens which failed prior to testing were included in the statistical analysis.

\section{Statistical analysis}

The influence of bleaching treatment on enamel bond strength at different elapsed times between end of bleaching treatment and the adhesive procedure was analyzed by one-way ANOVA and Tukey's test. All statistical analyses were performed at a pre-set alpha of 0.05 using SPSS 19 for Windows software (IBM Corp., Armonk, New York, USA).

\section{Failure mode analysis}

After $\mu$ TBS test, fractured surfaces were analyzed by a single operator under a stereomicroscope (Olympus SZX7, Olympus Co., Tokyo, Japan) at $\times 30$ magnification. Failure modes were classified as cohesive (in enamel or 
composite), adhesive (between adhesive and enamel), or mixed (adhesive and cohesive fractures occurred simultaneously).

\section{SEM and EDS analyses}

Representative specimens selected from each experimental group were visualized by gold sputtering (Bal-Tec SCD 005 Sputter Coater, Balzers, Liechtenstein) and analyzed under a scanning electron microscope (SEM; S3400N, Hitachi, Tokyo, Japan).

In addition, 20 bovine teeth were selected. Enamel specimens of $6 \mathrm{~mm} \times 8 \mathrm{~mm} \times 1 \mathrm{~mm}$ were obtained from central buccal surfaces and sectioned into two halves. They were ground with 600-, 1,200-, and 4,000-grit silicon carbide discs (BuehlerMet II, Buehler) and polished with diamond abrasives (9-, 3-, and 1- $\mu \mathrm{m}$; MetaDi, Buehler). Between each polishing step, specimens were ultrasonically cleaned for $10 \mathrm{~min}$ with distilled water. One of the halves was used as control and the other was treated with a bleaching product following the same procedures described above.

After bleaching treatment or non-treatment (control), all specimens were etched with $36 \%$ phosphoric acid for $30 \mathrm{~s}$ and ultrasonically cleaned for $10 \mathrm{~min}$. Specimens were dehydrated using increasing concentrations of ethanol of $25 \%$ for $20 \mathrm{~min}, 50 \%$ for
$20 \mathrm{~min}, 75 \%$ for $20 \mathrm{~min}$, $95 \%$ for $30 \mathrm{~min}$, and $100 \%$ for $60 \mathrm{~min}^{29)}$, and then stored in a desiccator. Quantitative elemental analysis of $\mathrm{Ca}$ and $\mathrm{P}$ by energy dispersive X-ray spectroscopy (EDS) was carried out in two randomly selected areas of each specimen at $\times 5,000$ magnification. An EDS probe (XL30, Edax, Mahwah, NJ, USA) coupled to the SEM (Phillips XL30 ESEM, FEI Company, Hillsboro, OR, USA) in environmental mode was used. Average percentage of both elements was recorded for control and treated surfaces and compared by Student's $t$-test for paired samples $(p<0.05)$. Finally, specimens were gold-sputtered and observed under SEM. Representative images were obtained at magnifications of $\times 5,000, \times 20,000$, and $\times 50,000$ and an accelerating voltage of $20-25 \mathrm{kV}$.

\section{RESULTS}

\section{pH values}

Table 2 shows the $\mathrm{pH}$ values determined for all the bleaching products tested in this study. All products showed $\mathrm{pH}$ values higher than 5, except for Clysiden gel with a $\mathrm{pH}$ value of 2.5 .

Microtensile bond strength

Table 3 shows the mean $\mu$ TBS and standard deviation

Table 3 Mean and standard deviation values of microtensile bond strength to enamel (MPa) obtained with the bleaching products tested at different elapsed times after bleaching treatment ( $n=$ number of beams tested)

\begin{tabular}{|c|c|c|c|c|c|c|c|c|c|c|}
\hline \multirow{2}{*}{$\begin{array}{l}\text { Group/Time elapsed } \\
\text { after bleaching }\end{array}$} & \multicolumn{2}{|c|}{ Immediately } & \multicolumn{2}{|l|}{1 day } & \multicolumn{2}{|l|}{3 days } & \multicolumn{2}{|l|}{7 days } & \multicolumn{2}{|l|}{14 days } \\
\hline & $\mu \mathrm{TBS}$ & $n$ & $\mu \mathrm{TBS}$ & $n$ & $\mu \mathrm{TBS}$ & $n$ & $\mu \mathrm{TBS}$ & $n$ & $\mu \mathrm{TBS}$ & $n$ \\
\hline No treatment & $26.0(8.7) \mathrm{a}$ & 35 & $24.4(5.5) \mathrm{a}$ & 35 & $26.7(6.9) \mathrm{a}$ & 32 & $25.8(8.4) \mathrm{a}$ & 27 & $26.8(6.1) \mathrm{a}$ & 28 \\
\hline Opalescence & $27.1(8.0) \mathrm{a}$ & 40 & $26.3(9.8) \mathrm{a}$ & 30 & $25.2(7.8) \mathrm{a}$ & 37 & $25.2(5.6) \mathrm{a}$ & 31 & $26.4(8.6) \mathrm{a}$ & 33 \\
\hline Opalescence Treswhite & $27.7(8.3) \mathrm{a}$ & 38 & $26.3(7.7) \mathrm{a}$ & 39 & $26.0(9.3) \mathrm{a}$ & 32 & $26.6(8.1) \mathrm{a}$ & 38 & $26.1(9.0) \mathrm{a}$ & 35 \\
\hline WhiteKin & $23.6(7.5) \mathrm{b}$ & 33 & $23.0(7.4) \mathrm{b}$ & 33 & $22.6(9.5) \mathrm{b}$ & 31 & $22.3(5.5) \mathrm{b}$ & 27 & $25.8(9.9) \mathrm{a}$ & 31 \\
\hline Clysiden & $19.9(5.6) \mathrm{c}$ & 38 & $18.9(6.4) \mathrm{c}$ & 31 & $18.7(6.2) \mathrm{c}$ & 31 & $19.6(6.1) \mathrm{c}$ & 30 & $25.6(4.2) \mathrm{a}^{*}$ & 31 \\
\hline
\end{tabular}

Different letters in the same column indicate statistically different microtensile bond strength values among bleaching products $(p<0.05)$.

* Means statistically different microtensile bond strength for specimens treated with the same bleaching product at different elapsed times $(p<0.05)$.

Table 4 Failure mode distribution (\%), where C: cohesive failure; A: adhesive failure; M: mixed failure

\begin{tabular}{|c|c|c|c|c|c|c|c|c|c|c|c|c|c|c|c|}
\hline \multirow{2}{*}{$\begin{array}{l}\text { Group/Time elapsed } \\
\text { after bleaching }\end{array}$} & \multicolumn{3}{|c|}{ Immediately } & \multicolumn{3}{|c|}{1 day } & \multicolumn{3}{|c|}{3 days } & \multicolumn{3}{|c|}{7 days } & \multicolumn{3}{|c|}{14 days } \\
\hline & $\mathrm{A}$ & $\mathrm{C}$ & M & $\mathrm{A}$ & $\mathrm{C}$ & M & $\mathrm{A}$ & $\mathrm{C}$ & M & $\mathrm{A}$ & $\mathrm{C}$ & M & $\mathrm{A}$ & $\mathrm{C}$ & $\mathrm{M}$ \\
\hline No treatment & 82.8 & 2.9 & 14.3 & 80.0 & - & 20.0 & 78.1 & - & 20.7 & 70.4 & 3.7 & 25.9 & 80.0 & - & 20.0 \\
\hline Opalescence & 80.0 & 2.5 & 17.5 & 80.0 & - & 20.0 & 78.4 & 2.7 & 18.9 & 71.0 & 6.5 & 22.6 & 90.3 & - & 9.7 \\
\hline Opalescence Treswhite & 78.9 & - & 21.1 & 84.6 & - & 15.4 & 81.3 & 6.3 & & 79 & 10.5 & 10.5 & 80 & - & 20.0 \\
\hline WhiteKin & 71.8 & 7.7 & 20.5 & 75.0 & 5.0 & 20.0 & 84.4 & - & 15.6 & 71.8 & - & 28.2 & 80 & 3.3 & 16.7 \\
\hline Clysiden & 68.4 & 21.1 & 10.5 & 67.7 & 16.1 & 12.9 & 77.4 & 16.1 & 6.5 & 70.0 & 10 & 20.0 & 80.6 & 14.4 & 20.0 \\
\hline
\end{tabular}


(sd) values expressed in MPa. Significant differences were detected among the bleaching products for several periods of elapsed time evaluated $(p<0.05)$. When the adhesive procedure was performed immediately, at 1,3 , or 7 days after the bleaching treatment, Clysiden-treated specimens showed the lowest $\mu$ TBS values followed by the WhiteKin group $(p<0.05)$. However, Opalescenceand Treswhite-treated specimens showed values similar to those obtained by the control group $(p>0.05)$.

When the adhesive procedure was performed at 14 days after the bleaching treatment, similar $\mu$ TBS values were obtained regardless of the bleaching product applied $(p>0.05)$.

\section{Failure mode}

On the overall, predominant failure mode among all the bleaching products and elapsed times was adhesive failure between enamel and the adhesive. However, Clysiden-treated specimens exhibited a higher percentage of cohesive failures in enamel compared with the other groups (Table 4).

\section{Surface morphology by SEM}

When compared with their controls, bleached specimens showed no obvious alterations in their surface morphology, except when treated with Clysiden (Fig. 1). Clysiden-treated specimens exhibited a more extensive and irregular etching pattern, showing wider
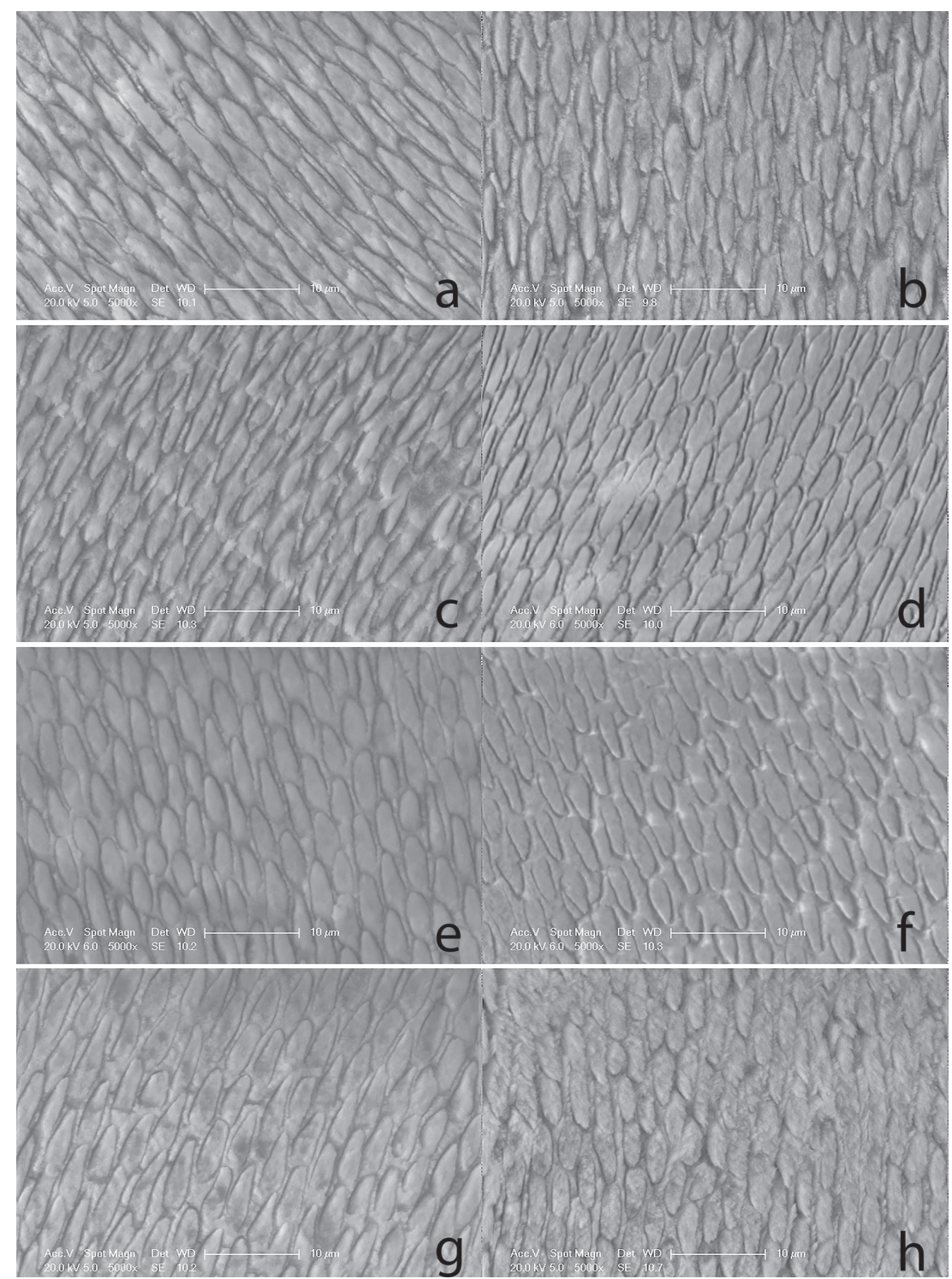

Fig. 1 Representative SEM micrographs of enamel surfaces.

Left images correspond to the control group, and right images show the same acid-etched specimens after bleaching with the different products tested at $\times 5,000$ magnification and $20 \mathrm{kV}$ accelerating voltage. (a, b):Opalescence; (c, d): Opalescence Treswhite; (e, f): WhiteKin; and (g, h): Clysiden. 

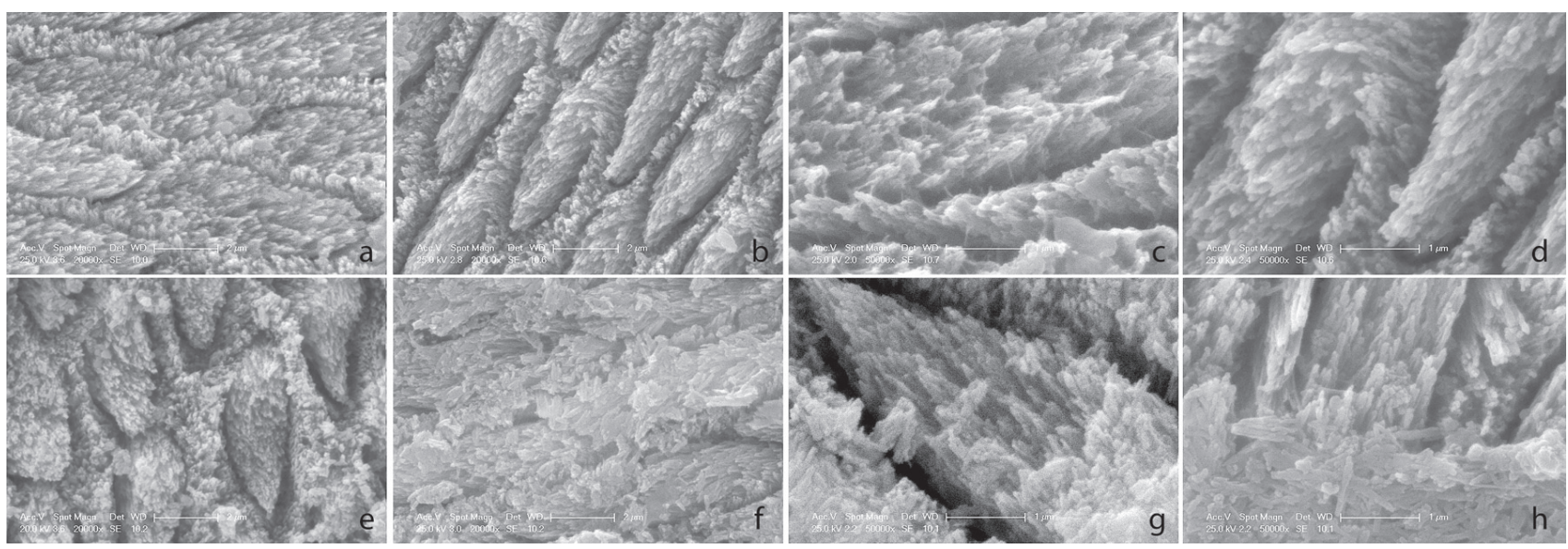

Fig. 2 Representative images of enamel surfaces from the Clysiden experimental group.

Upper-row images correspond to the control group, and lower-row images show the Clysiden-bleached specimens at $\times 20,000, \times 25,000$, or $\times 50,000$ magnification and $20-25 \mathrm{kV}$ accelerating voltage. Etching pattern is more extensive in the bleached specimens. Some areas show wider interprismatic spaces and others show higher mineral loss (e, g). In contrast, the etching pattern disappeared due to accumulation of crystals (f, h).

Table 5 Comparison of mean and standard deviation values of $\mathrm{Ca}$ and $\mathrm{P}$ (weight\%) between control and bleached specimens according to the bleaching product tested

\begin{tabular}{|c|c|c|c|c|c|c|c|c|}
\hline \multirow{2}{*}{ Group } & \multicolumn{2}{|c|}{ Ca control } & \multicolumn{2}{|c|}{ Ca bleached } & \multicolumn{2}{|c|}{$\mathrm{P}$ control } & \multicolumn{2}{|c|}{ P bleached } \\
\hline & $\mathrm{Wt} \%$ & $n$ & Wt \% & $n$ & $\mathrm{Wt} \%$ & $n$ & $\mathrm{Wt} \%$ & $n$ \\
\hline Opalescence & $38.9(1.7)$ & 10 & $37.9(0.7)$ & 10 & $17.6(1.5)$ & 10 & $17.7(1.4)$ & 10 \\
\hline Opalescence Treswhite & $39.0(0.5)$ & 10 & $39.6(0.9)$ & 10 & $17.6(0.8)$ & 10 & $17.6(1.1)$ & 10 \\
\hline WhiteKin & $37.5(0.5)$ & 10 & $38.1(0.3)$ & 10 & $17.6(0.3)$ & 10 & $17.4(0.2)$ & 10 \\
\hline Clysiden & $38.5(0.3)^{*}$ & 10 & $36.2(0.3)^{*}$ & 10 & $17.5(0.3)^{*}$ & 10 & $17.1(0.3)^{*}$ & 10 \\
\hline
\end{tabular}

* Means statistical differences in weight \% of Ca or P between control and bleached specimens

interprismatic spaces and higher mineral loss (Fig. 2).

\section{Ca and $P$ content}

Table 5 shows the EDS analysis results. Only specimens bleached with Clysiden exhibited a significantly lower content of $\mathrm{Ca}$ and $\mathrm{P}$ in comparison with their control.

\section{DISCUSSION}

When enamel was bleached with $10 \%$ carbamide peroxide gel (Opalescence) or 10\% hydrogen peroxide gel (Treswhite Supreme) in the present study, bond strength with resin composite was not affected regardless of the time elapsed between the end of bleaching treatment and the adhesive procedure. These results agreed with those obtained by Patusco et al. ${ }^{30)}$ with $10 \%$ carbamide peroxide, by Barbosa et al. ${ }^{31)}$ with $16 \%$ carbamide peroxide in an in situ study, and by Gurgan et al. at $30 \%$ concentration $^{32}$. At the same time, it must be pointed out that specimens were stored in artificial saliva and brushed twice per day with a fluoride paste to simulate realistic oral conditions. This could have contributed to enamel remineralization ${ }^{33,34)}$, and hence the results.

When enamel was bleached with OTC bleaching products WhiteKin and Clysiden, significantly lower microtensile bond strengths than those of the control group were obtained immediately, at 1, 3, and 7 days after the bleaching treatment.

The authors have reported a decrease in bond strength of resin composites to bleached enamel even when low-concentration bleaching products were used, such as $10 \%$ peroxide carbamide ${ }^{16,18,23}$. One commonly cited explanation was the presence of residual oxygen in bleached enamel pores, which then hampered the polymerization of resins ${ }^{13,26,35)}$. However, surface analysis techniques showed that oxygen did not accumulate within the near surface of bleached enamel ${ }^{15)}$. Nonetheless, if decreased bond strength were indeed caused by residual oxygen, this adverse effect could be eliminated by roughening the surface ${ }^{36)}$ or by applying phosphoric acid used in total-etch adhesive technique to 
remove this layer ${ }^{37)}$.

Other factors that might alter enamel adhesiveness must be considered. The authors have reported that peroxide-containing bleaching agents affected the organic phase of enamel, not only at the surface but also in the inner structure, as their low molecular weight allows them to rapidly penetrate the enamel ${ }^{17,33)}$. In fact, demineralization of enamel surface to a depth of $50 \mu \mathrm{m}$ has been described even for a $10 \%$ peroxide carbamide application ${ }^{38)}$. Morphology of enamel was altered due to loss of calcium and phosphate, and modifications in surface crystals were observed ${ }^{39)}$. Reduction in mineral content of enamel also led to increased superficial enamel porosity, overetched appearance, loss of prismatic structure, and decrease in microhardness ${ }^{14,33,37,40,41)}$. These effects remained after phosphoric acid etching since resin tags formed in bleached and etched enamel were less defined ${ }^{19)}$.

When compared with the control, specimens treated with Clysiden in this study showed a significant decrease in $\mathrm{Ca}$ and $\mathrm{P}$ content, loss of prismatic form, and a more aggressive etching pattern (Figs. 1 and 2). Accordingly, Clysiden-treated specimens had a higher percentage of cohesive failures in enamel.

The demineralizing effect of bleaching agents is attributed to their $\mathrm{pH}$ levels and is a determining factor in enamel adhesiveness: a greater loss of calcium and phosphorus is produced by phosphoric acid etching of enamel after bleaching ${ }^{14)}$. Enamel demineralization occurs at a $\mathrm{pH}$ lower than the 5.2-5.8 range $^{42)}$. In the present study, Clysiden showed the lowest $\mathrm{pH}$ values $-\mathrm{pH}$ of solution was 4.5 and that of gel (which included carbamide peroxide together with phosphoric acid and carbomer) was 2.5 .

For the other OTC product, WhiteKin, no information was found in published literature regarding its possible effect on enamel properties. To the best of the authors' knowledge, only a clinical study was published on this product's efficiency for dental whitening ${ }^{43)}$. WhiteKin-treated specimens exhibited lower microtensile bond strength when compared with the control. This result could stem from its composition, which included EDTA and citric acid, and that its $\mathrm{pH}$ ranged between 5 and 5.5. However, no statistical differences were found in microchemical composition after etching.

Although bleaching products may have a deleterious effect on resin composite bond strength to enamel, this effect is transient and enamel adhesiveness recovers after a waiting period. However, the amount of time required to return bond strength to normal is controversial, ranging from $24 \mathrm{~h}$ to 4 weeks, as reported in published literature ${ }^{23,26,44-48)}$. In the present study, bond strength to enamel was completely recovered after 14 days of storage in artificial saliva in the case of specimens bleached with WhiteKin and Clysiden Kit Express.

Based on the results of the present study, dentists should be aware of the possible negative effect of OTC bleaching products on enamel adhesiveness. Therefore, they should ask their patients whether they use any OTC products to avoid performing an adhesive procedure without a waiting period. In the case of WhiteKin and Clysiden Kit Express, the waiting period should be a minimum of 14 days.

\section{CONCLUSION}

Although resin composite bond strength to enamel could be affected with the use of low-concentration OTC bleaching products, it returned to normal after 14 days in artificial saliva storage. When compared with the unbleached control, Clysiden-treated specimens exhibited a significantly lower $\mathrm{Ca}$ and $\mathrm{P}$ content and a more irregular etching pattern after etching with phosphoric acid.

\section{ACKNOWLEDGMENTS}

Authors are indebted to Ultradent and Kin for providing the bleaching products used in this study and to Roberto García-Quismondo Castro for his help with SEM and EDS analyses. This study is part of a thesis to be submitted in partial fulfilment of the requirements for the $\mathrm{PhD}$ degree of author MC.

\section{REFERENCES}

1) Joiner A. Review of the effects of peroxide on enamel and dentine properties. J Dent 2007; 35: 889-896.

2) Hasson H, Ismail AI, Neiva G. Home-based chemically induced whitening of teeth in adults (Review). Cochrane Database Syst Rev 2006; 4: 1-43.

3) Haywood VB, Heymann HO. Nightguard vital bleaching: How safe it is? Quintessence Int 1991; 22: 515-523.

4) Ritter AV, Leonard RH Jr, St Georges AJ, Caplan DJ, Haywood VB. Safety and stability of nightguard vital bleaching: 9 to 12 years post-treatment. J Esthet Restor Dent 2002; 14: 275-285.

5) Dahl JE, Pallesen U. Tooth bleaching - a critical review of the biological aspects. Crit Rev Oral Biol Med 2003; 14: 292304.

6) Joiner A. The bleaching of teeth: A review of the literature. J Dent 2006; 34: 412-419.

7) Burrows S. A review of the efficacy of tooth bleaching. Dent Update 2009; 36: 537-538, 541-544, 547-548 passim.

8) Demarco FF, Meireles SS, Masotti AS. Over-the-counter whitening agents: a concise review. Braz Oral Res 2009; 23: 64-70.

9) Briso AL, Toseto RM, de Arruda AM, Tolentino, PR, de Alexandre RS, dos Santos PH. Evaluating the bonding of two adhesive systems to enamel submitted to whitening dentifrices. Acta Odontolol Latinoam 2010; 23: 111-116.

10) Kugel G. Over-the-counter tooth-whitening systems. Compend Contin Educ Dent 2003; 24: 376-382.

11) Dietschi D, Benbachir N, Krejci I. In vitro colorimetric evaluation of the efficacy of home bleaching and over-thecounter bleaching products. Quintessence Int 2010; 41: 505516.

12) Joiner A. Whitening toothpastes: a review of the literature. J Dent 2010; 38: e17-e24.

13) Titley KC, Torneck CD, Smith DC, Chernecky R, Adibfar A. Scanning electron microscopy observations on the penetration and structure of resin tags in bleached and unbleached bovine enamel. J Endod 1991; 17: 72-75. 
14) Josey AL, Meyers IA, Romaniuk K, Symons AL. The effect of a vital bleaching technique on enamel surface morphology and the bonding of composite resin to enamel. J Oral Rehabil 1996; 23: 244-250.

15) Perdigão J, Francci C, Swift EJ Jr, Ambrose WW, Lopes M. Ultra-morphological study of the interaction of dental adhesives with carbamide peroxide-bleached enamel. Am J Dent 1998; 11: 291-301.

16) Bulut H, Turkun M, Kaya AD. Effect of an antioxidizing agent on the shear bond strength of brackets bonded to bleached human enamel. Am J Orthod Dentofacial Orthop 2006; 129: 266-272.

17) Nour El-din AK, Miller BH, Griggs JA, Wakefield C. Immediate bonding to bleached enamel. Oper Dent 2006; 31: 106-114.

18) Barcellos DC, Benetti P, Fernandes VV Jr, Valera MC. Effect of carbamide peroxide bleaching gel concentration on the bond strength of dental substrates and resin composite. Oper Dent 2010; 35: 463-469.

19) da Silva BM, Flório FM, Basting RT. Shear bond strength of resin composite to enamel and dentin submitted to a carbamide peroxide dentifrice. Am J Dent 2007; 20: 319-323.

20) Araujo DB, Silva LR, de Araujo RP. Calcium release rates from tooth enamel treated with dentifrices containing whitening agents and abrasives. Gen Dent 2010; 58: e240245.

21) de Medeiros CL, González-López S, Bolaños-Carmona MV, Sanchez-Sanchez P, Bolaños-Carmona J. Effects of phosphoric acid on bovine enamel bleached with carbamide peroxide. Eur J Oral Sci 2008; 116: 66-71.

22) Torres-Rodríguez C, González-López S, Bolaños-Carmona V, Sánchez-Sánchez P, Rodríguez-Navarro A, Attin T. Demineralization effects of phosphoric acid on surface and subsurface bovine enamel bleached with in-office hydrogen peroxide. J Adhes Dent 2011; 13: 315-321.

23) Cavalli V, Reis AF, Giannini M, Ambrosano GM. The effect of elapsed time following bleaching on enamel bond strength of resin composite. Oper Dent 2001; 26: 597-602.

24) Miyazaki M, Sato H, Sato T, Moore BK, Platt JA. Effect of a whitening agent application on enamel bond strength of selfetching primer systems. Am J Dent 2004; 17: 151-155.

25) Unlu N, Cobankara FK, Ozer F. Effect of elapsed time following bleaching on the shear bond strength of composite resin to enamel. J Biomed Mater Res B Appl Biomater 2008; 84: 363-368.

26) Titley KC, Torneck CD, Ruse ND. The effect of carbamide peroxide gel on the shear bond strength of a microfill resin to bovine enamel. J Dent Res 1992; 71: 20-24.

27) Nakamichi I, Iwaku M, Fusayama T. Bovine teeth as possible substitutes in the adhesion test. J Dent Res 1983; 62: 10761081.

28) Esser M, Tinschert J, Marx R. Material characteristics of hard tissues of bovine versus human teeth. Dtsch Zahnärztl Z 1998; 53: 713-717.

29) Perdigão J, Lambrechts $P$, van Meerbeek $B$, Tomé AR, Vanherle G, Lopes AB. Morphological field emission-SEM study of the effect of six phosphoric acid etching agents on human dentin. Dent Mater 1996; 12: 262-271.

30) Patusco VC, Montenegro G, Lenza MA, Alves de Carvalho A. Bond strength of metallic brackets after dental bleaching. Angle Orthod 2009; 79: 122-126.
31) Barbosa CM, Sasaki RT, Flório FM, Basting RT. Influence of in situ post-bleaching times on resin composite shear bond strength to enamel and dentin. Am J Dent 2009; 22: 387392.

32) Gurgan S, Alpaslan T, Kiremitci A, Cakir FY, Yazici E, Gorucu J. Effect of different adhesive systems and laser treatment on the shear bond strength of bleached enamel. J Dent 2009; 37: 527-534.

33) Lewinstein I, Fuhrer N, Churaru N, Cardash H. Effect of different peroxide bleaching regimens and subsequent fluoridation on the hardness of human enamel and dentin. J Prosthet Dent 2004; 92: 337-342.

34) Miranda TA, Moura SK, Amorim VH, Terada RS, Pascotto RC. Influence of exposure time to saliva and antioxidant treatment on bond strength to enamel after tooth bleaching: an in situ study. J Appl Oral Sci 2013; 21: 567-574.

35) Dishman MV, Covey DA, Baughan LW. The effects of peroxide bleaching on composite to enamel bond strength. Dent Mater 1994; 10: 33-36.

36) Cvitko E, Denehy GE, Swift EJ Jr, Pires JA. Bond strength of composite resin to enamel bleached with carbamide peroxide. J Esthet Dent 1991; 3: 100-102.

37) McCracken MS, Haywood VB. Demineralization effect of 10 percent carbamide peroxide. J Dent 1996; 24: 395-398.

38) Efeoglu N, Wood D, Efeoglu C. Microcomputerised tomography evaluation of $10 \%$ carbamide peroxide applied to enamel. J Dent 2005; 33: 561-567.

39) Soares DG, Ribeiro AP, Sacono NT, Loguércio AD, Hebling J, Costa CA. Mineral loss and morphological changes in dental enamel induced by a $16 \%$ carbamide peroxide bleaching gel. Braz Dent J 2013; 24: 517-521.

40) Ben-Amar A, Liberman R, Gorfil C, Bernstein Y. Effect of mouthguard bleaching on enamel surface. Am J Dent 1995; 8: 29-32.

41) Hegedüs C, Bistey T, Flóra-Nagy E, Keszthelyi G, Jenei A. An atomic force microscopy study on the effect of bleaching agents on enamel surface. J Dent 1999; 27: 509-515.

42) Salomão D, Santos D, Nogueira R, Palma-Dibb R, GeraldoMartins V. Acid demineralization susceptibility of dental enamel submitted to different bleaching techniques and fluoridation regimens. Oper Dent 2014; 39: E178-E185.

43) Forner L, Amengual J, Liena C, Riutord P. Therapeutic effectiveness of a new enzymatic bleaching dentifrice. Eur $\mathrm{J}$ Esthet Dent 2012; 7: 62-70.

44) McGuckin RS, Thurmond BA, Osovitz S. Enamel shear bond strengths after vital bleaching. Am J Dent 1992; 5: 216-222.

45) Miles PG, Pontier JP, Bahiraei D, Close J. The effect of carbamide peroxide bleach on the tensile bond strength of ceramic brackets - an in vitro study. Am J Orthod Dentofacial Orthop1994; 106: 371-375.

46) Mullins JM, Kao EC, Martin CA, Gunel E, Ngan P. Tooth whitening effects on bracket bond strength in vivo. Angle Orthod 2009; 79: 777-783.

47) Nascimento GC, de Miranda CA, Machado SM, Brandão GA, de Almeida HA, Silva CM. Does the time interval after bleaching influence the adhesion of orthodontic brackets? Korean J Orthod 2013; 43: 242-247.

48) Bittencourt BF, Dominguez JA, Loguercio AD, Gomes JC, Gomes OM. Influence of two different methods of delivering fluoride on bond strength and degree of conversion of an adhesive after bleaching. J Adhes Dent 2013; 15: 553-559. 